\title{
A imagem da ciência e dos cientistas: retratos de um estudo na Universidade do Minho
}

\section{The image of science and scientists: portraits of a study at the University of Minho}

\author{
Ricardina Magalhães*, Teresa Ruão** \\ * Centro de Estudos de Comunicação e Sociedade - Universidade do Minho, Portugal \\ ** Centro de Estudos de Comunicação e Sociedade - Universidade do Minho, Portugal
}

Resumo

\begin{abstract}
A divulgação e disseminação da ciência dá-se em diferentes contextos e através de diversas atividades. Contudo, é na universidade onde a promoção da ciência tem mais potencial de impacto, nomeadamente pela exposição das pessoas aos eventos científicos realizados, às obras de cariz científico publicadas e ao contacto direto com investigadores. As atividades de divulgação criam representações mentais sobre a ciência junto dos públicos, que, no seu conjunto, dão origem a uma imagem mais ou menos estável. E dessa imagem resulta um certo nível de reconhecimento e um consequente apoio às atividades dos investigadores, e à ciência por inerência, pelas comunidades e decisores políticos.

Interessa, por isso, conhecer as perceções sobre a ciência, nomeadamente perceber a imagem que os estudantes do Ensino Superior têm da atividade científica - isto é, indivíduos jovens a viver num contexto privilegiado de contacto com a ciência. A esse propósito quisemos saber se os alunos de uma universidade têm consciência do permanente contacto com a ciência; o que constitui a ciência para esses estudantes; de que forma se pode levar os estudantes ao contacto positivo com ciência; de que modo podem os investigadores influenciar a imagem projetada da ciência; e como podem as instituições científicas influenciar a imagem percebida da Ciência juntos dos estudantes.

Para obter estas respostas, conduzimos um estudo-piloto através da aplicação de um questionário a alunos dos três ciclos de estudos da Universidade do Minho, em vários cursos de áreas científicas distintas. Em suma, procurámos perceber qual era a sua perceção/imagem da ciência e da investigação científica naquele contexto, na busca de orientações para um trabalho de qualidade na comunicação da ciência em Portugal.
\end{abstract}

Palavras-chave: ciência; investigação científica; imagem da ciência, perceção da ciência; Universidade do Minho

Abstract

The disclosure and dissemination of science occurs in different contexts and through various activities. However, it is at the university where the promotion of science has more potential for impact, namely by the exposition to scientific events, the scientific published works nature and the direct contact with researchers. Dissemination activities create mental representations about science among the public, which, on the whole, give rise to a more or less stable image. And from this image results a certain leve of recognition and a consequent support to the activities of researchers, and to science inherently, by communities and policy makers.

It is relevant, therefore, to know the perceptions about science, namely to perceive the image that the students of Higher Education have of the scientific activity - that is, young individuals to live a privileged context of contact with science. In this regard we wanted to know if the students of a university are aware of permanent contact with science; what is science for these students; how students can be brought into positive contact with science; how researchers can influence the projected image of science; and how can scientific institutions influence the perceived image of science together with students. To obtain these answers, we have conducted a pilot study by applying a questionnaire to students of the three cycles of studies of the University of Minho (Portugal), in various courses of different scientific areas. In short, we sought to understand what their perception / image of science and scientific research was in that context, in search of guidelines for quality work in science communication in Portugal.

Keywords: Science; scientific research; image of science; perception of science; University of Minho 


\section{Introdução}

Como sugere a literatura, é na universidade que a promoção da ciência apresenta um maior potencial, pela frequente exposição dos jovens estudantes ao trabalho dos investigadores, que são, muitas vezes em simultâneo, seus professores. Este contacto pode dar-se através da participação em eventos científicos a acontecer nas academias (por exemplo congressos, seminários, colóquios, palestras ou workshops), pela leitura de publicações especializadas (disponíveis nas bibliotecas, com uma vasta oferta de livros e artigos nacionais e internacionais, ou mesmo apresentados em sessões de lançamento e promoção das obras dos investigadores que são docentes da Universidade em que trabalham) ou tão-somente pela frequência das aulas.

Assim, neste contexto, a construção da imagem da ciência acontece, primeiramente, pela mão dos investigadores / docentes que estimulam o desenvolvimento de representações mentais de forma intensiva. Por isso, para perceber como podemos promover uma imagem positiva e atrativa da ciência junto de uma parte relevante dos jovens da sociedade atual, importa conhecer que perceção que têm os estudantes do Ensino Superior da atividade científica. Nessa medida, fomos procurar as respostas na Universidade do Minho, pela proximidade que as autoras deste estudo-piloto têm com os alunos da instituição. Considerámos pertinente analisar a perceção / imagem que os estudantes do Ensino Superior têm sobre a ciência, para pensar a forma como as Universidades podem atuar na melhoria da compreensão, envolvimento e interesse destes públicos pela ciência e, eventualmente, na capacidade de atração dos jovens para a prática da atividade científica. A atração de jovens talentos para a ciência tem sido uma preocupação crescente dos estados e comunidades, como defende Csermely (2003), pela sua influência no desenvolvimento dos países. $\mathrm{E}$, como salienta o autor, o contacto privilegiado com a investigação científica - que pode acontecer dentro da universidade com estes jovens estudantes - será uma força motriz no que respeita à captação de futuros investigadores.

Para atingir estes propósitos, neste artigo discutimos os processos de construção da imagem da ciência junto dos jovens a partir do conhecimento gerado em duas áreas de especialidade das Ciências da Comunicação: a Comunicação da Ciência e a Comunicação Estratégica. Ou seja, procuramos trazer o conhecimento desenvolvido na comunicação estratégica para a atuação da comunicação da ciência, analisando as perceções de imagem já geradas, e pensando em estratégias que podem ser utilizadas para melhorar a performance comunicacional das universidades na prossecução deste objetivo.

O porquê deste estudo reside nalgumas das conclusões do Eurobarómetro aplicado em 2001 (levado a cabo pela Comissão Europeia) em que se aponta, entre outras conclusões, que "a falta de interesse dos jovens pelo estudo das ciências" se devia ao seu "caráter pouco apelativo e à dificuldade inerente aos assuntos apresentados", e que "dois terços dos europeus se consideravam mal informados sobre C\&T" (Martins, 2015, p. 41).

Da mesma forma, o mesmo estudo assinala que, na generalidade, os europeus

"têm uma imagem positiva sobre C\&T mas é menos clara a imagem sobre o trabalho dos cientistas. Partilham uma visão otimista sobre o impacte da C\&T. Consideram que o público deveria ser consultado sobre decisões tomadas pelos cientistas sobre ciência e os cientistas deveriam comunicar melhor sobre ciência com o público. Não sabem 
qual é o investimento em ID mas, em geral, concordam que deveria aumentar. Verifica-se também que quem está interessado e informado acerca de C\&T partilha uma visão mais positiva e $75 \%$ dos cidadãos EU27 consideram que a C\&T trará mais oportunidades para as futuras gerações. Deste estudo resulta uma visão de que a C\&T é um campo em rápida e profunda evolução com impacte nas sociedades" (Martins, 2015, p. 42)

\section{A comunicação da ciência e a promoção de uma imagem da ciência e dos cientistas}

A construção de uma imagem positiva e valorizadora da ciência e dos cientistas só acontece com uma comunicação eficaz, já que uma "comunicação ineficaz pode sair cara tanto para a ciência, como para a sociedade. [Pois a] ciência requer o apoio do público. E isso está próximo de acontecer, [mas] depende de quanto o público confia e valoriza a ciência" (Fischhoff \& Scheufele, 2013, p. 14031). Aliás, o ideal parece ser o desenvolvimento de uma cultura de ciência nas sociedades, por via da educação, como forma de incorporar o seu valor social. E a comunicação da ciência é o que possibilita que o conhecimento científico seja absorvido na cultura de uma comunidade mais ampla (Bryant, 2003). Na verdade, a comunicação permite criar uma ponte entre a comunidade de investigação científica e a sociedade civil, desde logo, um objetivo reforçado pela Comissão Europeia, nomeadamente através do programa de financiamento "Horizonte 2020", que valoriza o denominado public engagement. Um conceito que exprime o entendimento de que mais do que conhecer o trabalho da ciência, se deve procurar que o público seja capaz de se envolver com esse trabalho. E a Comissão Europeia definiu este public engagement como uma meta do "Horizonte 2020", afirmado que, no que respeita à "Responsible Research and Innovation - RRI" [investigação e inovação responsáveis] - uma ação-chave do objetivo "Ciência com e para a sociedade" da Comissão Europeia, inserido no programa de financiamento "Horizonte 2020" -, se deve procurar a "cocriação do futuro com cidadãos e organizações da sociedade civil", juntando a "mais ampla diversidade de atores que normalmente não interagiriam entre si em questões de Ciência e Tecnologia" 1 .

$\mathrm{Na}$ defesa do public engagement, a Comissão Europeia acrescenta ainda que este: i) contribui para a construção de uma sociedade cientificamente mais literata, capaz de participar ativamente e de apoiar os processos democráticos e os desenvolvimentos científicos e tecnológicos: ii) introduz perspetivas diferentes e criatividade na construção e nos resultados da investigação; e iii) contribui para promover os resultados da investigação e inovação mais relevantes e desejáveis em termos societais, ajudando-nos a enfrentar os desafios da sociedade.

Assim, o public engagement parece implicar e proporcionar, ao mesmo tempo: i) o estabelecimento de diálogos participativos e interativos entre investigadores, políticos, organizações da indústria e da sociedade civil, ONGs e cidadãos; ii) o fomento da compreensão mútua e a cocriação de resultados de investigação e inovação, e agendas políticas eficazes na resposta aos desafios societais; e iii) a promoção de uma maior aceitabilidade dos resultados. O public engagement, de acordo com a Comissão Europeia, pode ainda ser

\footnotetext{
${ }^{1}$ Toda a informação aqui apresentada sobre o public engament e o programa Responsible Research and Innovation está disponível em http://ec.europa.eu/programmes/horizon2020/en/h2020-section/public-engagement-responsibleresearch-and-innovation
} 
"especificamente solicitado ou incorporado voluntariamente em projetos, para promover resultados socialmente mais relevantes" ${ }^{\prime 2}$. E o cenário ideal para a criação desse engagement seria o de o incorporar nos projetos e no processo de investigação desde o seu início e de forma interativa, para que as aprendizagens possam contribuir para enriquecer o processo e os resultados.

Ora, este public engagement é promovido através das ações de comunicação da ciência, que, para além de procurarem levar o conhecimento à comunidade não científica, cumprem o papel de reforço democrático e de desenvolvimento social. Como defende Amadou Mahtar (ex-diretor geral da UNESCO, citado em Hernando, 2006, s. p.), "ao promover uma compreensão cabal dos alcances e das implicações dos descobrimentos e invenções, a divulgação científica converteu-se num instrumento da democracia moderna, capaz de ajudar os cidadãos nas suas opções e aos responsáveis nas suas decisões".

Da mesma forma, Tintori sustenta que a comunicação da ciência é um elemento vital para o bom funcionamento social, afirmando que

não deve ser apenas para os cientistas, porque é importante demais: é o meio pelo qual exploramos o mundo natural e social e é a forma dominante - e atualmente a única legítima - do conhecimento humano. Para o bem da sociedade, o progresso público e científico em si, a ciência precisa de uma comunidade mais ampla e os seus resultados devem ser comunicados ao público em geral de forma correta e envolvente. (2017a, pp. 15-16)

Aliás, nos trabalhos que já realizámos (Magalhães, 2014, 2015; Ruão, Neves \& Magalhães, 2015) falámos da importância vital da comunicação da ciência, que responde a um compromisso com a própria ciência. Mas, apesar disto, a comunicação no universo científico é ainda maioritariamente entendida como divulgação científica, ou seja, é vista tão-somente como:

o exercício através do qual os produtores de conhecimento científico - cientistas - dão a conhecer o resultado do seu trabalho a destinatários não-especialistas - leigos. Os objectivos subjacentes a este exercício são díspares embora tenham em comum a preocupação de divulgar o conhecimento científico junto dos que não integram a comunidade de cientistas assim fomentar uma maior compreensão da mesma. (Fernandes, 2011, p. 93)

Contudo, nos últimos anos, tem-se afirmado uma visão mais ampla do que pode e dever ser a comunicação da ciência. E Davies e Horst (2016), no livro Science communication: culture, identity and citizenship, sustentam essa definição abrangente da comunicação da ciência:

definimos comunicação da ciência como as ações organizadas com o objetivo de comunicar o conhecimento científico, metodologia, processos ou práticas em ambientes onde os não-cientistas são uma parte reconhecida do público. Esta é uma

\footnotetext{
${ }^{2}$ Retirado de http://ec.europa.eu/programmes/horizon2020/en/h2020-section/public-engagement-responsible-research-
} and-innovation 
definição ampla. Inclui apresentações da ciência nos mass media; materiais de informação destinados a pacientes ou grupos de utilizadores de tecnologias específicas; ciência em museus; festivais de ciência, eventos e oficinas; palestras e debates públicos; e ciência online e nos média sociais. A comunicação da ciência ocorre, portanto, em qualquer lugar. (Davies \& Horst, 2016, p. 4)

Granado e Malheiros, por seu lado, defendem que a comunicação da ciência compreende todas as atividades que permitem transmitir o saber científico, os resultados obtidos na investigação ou a informação sobre o contexto em que esta se produz. E vão mais longe, ao não fazerem distinção quanto às áreas científicas ou aos públicos destinatários das atividades de comunicação da ciência. Para eles, tudo é comunicação da ciência. Por isso, não fazem diferenciação quanto ao contexto em que se produz esta comunicação, às ferramentas utilizadas para veicular a informação, ou aos objetivos que se pretendem alcançar. Consideram como comunicação da ciência todas as formas de interação e promoção utilizadas por profissionais que trabalham nos mais variados locais de produção ou divulgação científica, tais como: museus, centros de ciência, gabinetes de comunicação das universidades, laboratórios e centros de investigação, meios de comunicação social, etc. Os autores consideram que esta é a expressão "mais genérica, mais vaga, mais inclusiva", já que cobre todas as atividades em que "a ciência se cruza com a comunicação" (2015, p. 16). Posto isto, percebe-se que comunicar a ciência não pode ser apenas dar a conhecer o avanço no conhecimento produzido pela investigação científica entre pares. Mas, como Bauer (2008, p. 22), acreditamos que se a ampla e tradicional missão da comunicação da ciência inclui: i) promover a literacia científica pública; ii) promover uma imagem positiva da ciência e iii) gerar a aceitação pública das novas tecnologias.

Portanto, comunicar a ciência para que se compreenda a própria ciência é imperativo, até para que se lhe atribua um lugar de reconhecimento na sociedade. Senão vejamos: numa época de restrições orçamentais como a que atravessamos, em que, por exemplo, se exigem cortes na despesa pública, a compreensão e valorização da ciência determinam a aceitação pública dos investimentos, ou não investimentos, que são feitos nesta área. A tomada de decisão política é, pois, muitas vezes a alavanca que gera a necessidade da sua comunicação.

A preocupação com a comunicação da ciência, que pode começar como uma ação de apelo ao financiamento público - quer por razões económicas, quer políticas -, acaba muitas vezes por ser tornar numa missão maior de formar uma sociedade de indivíduos informados, conscientes e capazes de tomar decisões acertadas sobre a vida individual de cada um e sobre a vida na comunidade em que se inserem. Ou seja, a preocupação inicial de favorecer o crescimento económico, através de uma política sustentada de Ciência e Tecnologia, pode acabar por tornar-se num movimento cívico que integra a responsabilidade social da ciência e dos cientistas de formar cidadãos melhores, mais informados, mais conscientes, mais ativos e com maior capacidade de decisão. E aqui reside a importância de comunicar a ciência: formar uma sociedade capaz de integrar todo o conhecimento científico na sua própria evolução.

Gregory e Miller (1998a, 1998b) mostram-nos que a comunicação da ciência é tão antiga quanto a própria ciência, uma vez que a comunicação, a disseminação, ou a divulgação da ciência, não são, de facto, fenómenos recentes, pois têm vindo a ser desenvolvidos desde o século XVII, nomeadamente através da criação de disciplinas dedicadas ao conhecimento científico e vocacionadas para estimular a transmissão do 
próprio conhecimento científico. Nessa altura surgiram também as primeiras palestras, fomentadas pelas classes altas, nos salões e ainda fora do ambiente académico. No século XVIII, com a abertura da responsabilidade de financiamento da ciência para os organismos privados, a disseminação do conhecimento científico tornou-se ainda mais imperativo. A partir dessa altura, há então uma proliferação do conhecimento científico junto de vários públicos. Mas, e paradoxalmente, a passagem para o século XX tornou a ciência trivialmente familiar, pela proliferação dos dispositivos eletrónicos um pouco por todo o lado, enquanto fez emergir uma ciência ambiguamente inacessível, pela multiplicação de um vasto conhecimento científico mas desigual para os diferentes campos de estudo (Gregory \& Miller, 1998b). Com esta mudança, alia-se à prática científica a responsabilidade de "prestar contas" sobre os avanços, recuos e resultados obtidos. E a importância que a ciência assume dentro de uma sociedade passa a depender da sua comunicação. É somente através desta que é possível despoletar um conjunto de perceções sobre a ciência, gerando imagens sobre a mesma e permitindo um reconhecimento da sua importância no progresso da humanidade. A comunicação da ciência é, por isso, a atividade que gerará perceções sobre a ciência e sobre os cientistas, de tal forma que, ao longo do tempo se possa criar um conjunto dessas mesmas perceções - a imagem que poderá ser positiva ou negativa. Esta imagem, este conjunto alargado de perceções, implica que a pessoa seja capaz de ter uma opinião sobre a ciência, que se quer informada e completa. Para tal, a ciência deve ser dada a conhecer como um todo, desde o seu processo, às suas limitações e consequências. Mostrar a ciência por inteiro aos jovens, por exemplo, será o que pode, no futuro, ditar a escolha de uma carreia na ciência, o que contribuirá para o avanço da ciência como resultado da atividade de investigação. Deve, por isso, mostrar-se a ciência como área de produção de conhecimento de forma atrativa, como atividade que "explora o mundo além das limitações atuais do conhecimento, desafia a 'sabedoria' e procura respostas" (Csermely, 2003, p. 825). Para o autor,

a liberdade de pensamento dos cientistas, a capacidade de satisfazer a sua própria curiosidade e a possibilidade de obter novos insights sobre o mundo natural são provavelmente os aspetos mais atrativos da investigação científica e podem explicar por que muitos cientistas se sentem mais comprometidos com o seu trabalho do que digamos, contabilistas ou trabalhadores de linha de fábricas. Assim, a ciência e a investigação oferecem uma oportunidade única e incomparável para que os jovens preencham a sua ânsia de respostas e explorem os seus pontos fortes e as suas habilidades intelectuais. (Csermely, 2003, p. 825)

Não há consenso sobre a razão que leva os cientistas a perceberem que comunicar os resultados da investigação científica por eles realizada é importante. O que acontece é que alguns o fazem de modo mais amplo e outros de uma forma mais restrita, apenas com os pares. Mas levar a ciência até aos jovens, procurando atraí-los para ela tornou-se uma preocupação internacional crescente, a ponto de se ter estimado que a Europa precisou de "atrair e treinar entre 600.000 e 700.000 novos investigadores até 2010 para ir ao encontro das suas necessidades de investigação" (Tintori, 2017b, p. 83). Por isso, trabalhar a imagem dos cientistas e da própria ciência é um imperativo de importância crucial para o desenvolvimento da ciência enquanto atividade que sobrevive com a renovação dos seus investigadores. Mas "para a maior parte da população, a realidade da ciência é aquela que é apresentada pelos meios de comunicação de 
massa. O público, em geral, conhece a ciência menos pela experiência direta ou a educação prévia do que através do filtro da linguagem e das imagens do jornalista" (Epstein, 1998, p. 60).

Assim, consideramos que a comunicação da ciência pode beneficiar muito do reconhecimento dos princípios da Comunicação Estratégica, uma outra área científica ligada aos estudos da comunicação, habituada a lidar com o desafio de fazer chegar informação ao espaço público. Planear a comunicação, os suportes e os meios de difusão, tendo bem presentes as metas e objetivos previamente definidos pode muito bem ser o salto que permitirá não só a criação e manutenção de uma imagem positiva da ciência, mas também a agregação do interesse dos jovens estudantes por uma área que tem tanto de atrativa, como tem de desincentivadora. Porque a ciência, e a sua comunicação, "não pode[m] mais ser interpretada[s] apenas como a[s] atividade[s] de cientistas individuais. É também institucional e profissional e pode ser entendida como uma forma de comunicação organizacional em universidades e outras organizações de investigação" (Horst, Davies \& Irwin, 2008, p. 893). Diga-se que, sem a comunicação da ciência, não há forma nem de se fomentar a compreensão da ciência, nem de estimular o compromisso entre as comunidades científica e não cientifica, para que seja possível continuar a acreditar na ciência e a validá-la como elemento social e cultural de relevo. E porque popularizar a ciência não é uma tarefa fácil, já que torná-la muito simples, inspirará poucos, torna-la muito difícil, fará com que ninguém se interesse por ela (Tintori, 2017a, p. 15).

\section{A comunicação estratégica}

A Comunicação Estratégica é um campo científico recente que derivou dos estudos da Comunicação Organizacional, mas que rapidamente assumiu uma posição de relevo nas organizações devido ao seu "carácter estratégico, que a levou a ocupar um lugar dominante nas posições de topo do organigrama" (Carrillo, 2014, p. 71). Na visão da autora, de resto, a área da Comunicação Estratégica distingue-se pela sua orientação para metas a alcançar e decisões a adotar para o efeito, numa visão muito funcionalista da organização. Sumariamente, a autora define o campo da seguinte forma:

O esforço de gestão da comunicação a longo prazo exigido a uma organização, no seu ambiente específico, para que a sua relação com os stakeholders aproveite a sua evolução, no sentido de atingir os objetivos estabelecidos com base na perspetiva e na visão da sua estratégia global. Será operacionalizado um mecanismo de ações táticas que se dividirão, elas próprias, em planos de ação de comunicação com um prazo claramente definido, de modo a alcançar os objetivos definidos a priori. (2014, p. 78)

Esta abordagem à comunicação organizacional implica, assim, a definição de estratégias de comunicação para atingir resultados de performance, exigindo a determinação de objetivos e metas dentro da organização, bem como uma avaliação de resultados. Nessa medida, Carrillo defende que a comunicação estratégica é "uma comunicação gerida" (2014, p. 76), através da consideração de "todas as formas de comunicação disponíveis para satisfazer os seus objetivos" (p. 76), criando o que se designa por "comunicação integrada" (Carrillo, 2014; Kunsch, 1986). 
Halahan, Holtzhausen, Ruler, Vercic e Sriramesh (2007), aliás, ressaltam a importância dessa visão integrada na definição que apresentam de comunicação estratégica, como: o "uso intencional da comunicação por uma organização para cumprir a sua missão" (2007, p. 3). E acrescentam, "a comunicação estratégica examina a comunicação organizacional sob um ponto de vista integrado e multidisciplinar, através de ideias e questões alargadas baseadas em várias disciplinas de comunicação tradicionais" (Hallahan et al., 2007, p. 4). Estas disciplinas referidas pelos autores mais não são do que áreas tradicionais da comunicação nas organizações, como: o marketing, as relações públicas, as tecnologias de comunicação, as políticas de comunicação e as campanhas de marketing social ou informativo (Hallahan et al., 2007).

Para além do exposto, os autores reforçam que a comunicação estratégica integra a prática deliberada e intencional do uso da comunicação para o cumprimento das metas organizacionais, noção comum à definição apresentada por Cheney et al. (2011, p. 126):

"a noção de que as organizações, a fim de estabelecer a sua presença e legitimidade no mercado, devem comunicar de forma consistente com diferentes públicos e em diferentes meios de comunicação. Ao coordenar e alinhar todas as mensagens da organização (incluindo visões, estratégias e temas de identidade), as organizações buscam a comunicação integrada esperando criar uma impressão unificada de que a organização é o que ela significa".

Argenti, Howell e Beck (2005, p. 83) por seu lado definem-na como sendo "a comunicação alinhada com a estratégia global da empresa, por forma a reforçar o seu posicionamento estratégico". Ou seja, os autores defendem que comunicação é tão importante na implementação da estratégia global de uma empresa que "quando as empresas usam uma abordagem estratégica da comunicação, esta torna-se parte integrante da formulação e da implementação da estratégia" (Argenti et al., 2005, p. 84).

Resumidamente, e além de exigir claridade e consistência na mensagem,

requer uma abordagem integrada e a vários níveis. Cada função da comunicação cumpre objetivos específicos, é segmentada para elementos particulares que são cruciais para a prossecução desses objetivos e é canalizada através dos canais mais apropriados e efetivos para esses elementos. Para alcançar um impacto estratégico na plenitude, todas as comunicações dirigidas a todos os elementos, através de todos os canais disponíveis, devem ser personalizadas de acordo com determinado objetivo, e ainda assim consistentes com todos os outros objetivos e com a estratégia da empresa. (Argenti et al., 2005, p. 87)

Um dos inquiridos deste estudo de Argenti et al. (2005), Michael Dell, o presidente da empresa Dell, chega mesmo a apontar que "uma parte fundamental da estratégia é comunicá-la" (p. 84). Uma posição consonante com Ruão que complementa a definição de comunicação estratégica, ao afirmar que esta

coloca a "influência propositada" no centro dos objetivos da comunicação das organizações, como a forma adequada destas cumprirem a sua missão, incluindo no 
seu campo o estudo da comunicação com os stakeholders, da comunicação da mudança, da comunicação participativa e outras análises complexas do ambiente organizacional. $(2016$, p. 43)

A autora acrescenta que a comunicação estratégica, sendo uma atividade intencional e orientada para atingir os objetivos organizacionais, procura fazê-lo através da identificação de atores-chave, da definição de objetivos estratégicos, do planeamento milimétrico, da implementação controlada e da avaliação regular da comunicação. Tudo isto com vista ao desenvolvimento de uma imagem desejada, cujo processo de construção analisaremos de seguida.

\section{Dos estudos de imagem na tradição organizacional}

O conceito de "imagem" surge nos estudos organizacionais por volta da década de 1950 e foi identificado como um conceito vital para as organizações modernas. É também visto como um dos pilares, a par da cultura organizacional e da comunicação, da metáfora da "organização expressiva", conceptualizada por Schultz, Hatch \& Larsern (2000), ou seja, da dimensão simbólica e expressiva das organizações.

Buscando-se a etimologia do termo, encontramos, por um lado Cutlip (1994) que acentua a sua versão originária do Latim imitare, que significa imitação; e por outro lado, Stern, Zinkhan e Jaju (2001) que enfatizam a raiz etimológica grega do conceito, ou seja a palavra ikon que personifica a representação na mente. Quer se opte por uma língua ou outra, ambas apontam a natureza mental do processo, sendo que, portanto, se trata sempre de uma representação mental do mundo real. No caso das organizações, a imagem organizacional tratar-se-á então da representação mental das mesmas, como um conjunto de perceções. Este conceito é construído, na perspetiva de Villafañe $(1996,1998)$, com base em dois processos: a perceção, que mais não é do que a seleção dos elementos do mundo real que mais chamam a atenção, e a representação, que tenta explicar uma realidade. Para o autor, as imagens mais não são do que "modelos de realidade", criados a partir dos mecanismos mentais que envolvem a perceção (que inclui a seleção, a abstração e a síntese). Estes mecanismos extraem elementos da realidade, conforme a intencionalidade do emissor. No seu todo, as perceções, que se vão agregando na mente dos recetores, formam uma imagem. Ora, a imagem que se forma de uma organização não é diferente disto, pelo que se pode considerar tratarse de uma representação mental da mesma, que integra os processos de perceção (neste caso trata-se de selecionar os elementos que caracterizam a organização) e de representação (que se traduz numa forma específica de 'ver' a organização). A comunicação tem, então um papel preponderante quer na projeção da imagem (como produtora das impressões), que corresponde à imagem projetada, quer na perceção dessas mesmas impressões e na retenção mental das mesmas, que corresponde à imagem percebida, formando um todo: a imagem organizacional.

Este conceito é fundamental para uma organização porque se traduz numa

impressão subjectiva na mente de uma pessoa. É a soma total do conhecimento, sentidos e impressões acerca de uma actividade, atitude ou serviço de uma empresa, 
marca ou produto. A imagem não representa apenas a qualidade real, mas também a qualidade imaginada ou atribuída. (Kennedy, 1977, p. 130)

O conceito foi tão útil para o desenvolvimento e evolução da Teoria da Comunicação Organizacional que foi assumido como um elemento estratégico, enquanto mecanismo de criação de valor simbólico para a organização, que se refletiria no sucesso da sua oferta comercial. Ruão (2016) lembra que a imagem é a "representação-reflexo da projeção organizacional, em resultado do cruzamento de mensagens no universo interno e externo" (p. 62). Refira-se também que não existe uma imagem da organização, como nos lembra Dowling (1986, p. 110): "uma empresa não tem uma imagem - as pessoas têm imagens da empresa". Na verdade, uma organização é representada por uma infinidade de imagens, consoante os seus stakeholders (lembramos que este conceito representa todos os públicos estratégicos, com algum interesse na organização). Cada um deles terá uma imagem, ou uma representação mental da organização, diferente de todos os outros, à medida das impressões que foi recolhendo e processando.

Aplicando estas ideias à imagem da ciência e dos cientistas podemos dizer que se trata de representações mentais sobre os atributos que caraterizam o trabalho do setor e dos seus investigadores, construídos com base na mensagens que os públicos destes recebem, intencionalmente ou não. Nestes públicos, salientamos os seus pares (especialistas) e a comunidade em geral (não especialistas), sendo um segmento destes últimos que nos interessou estudar.

\section{Metodologia}

Realizada uma revisão teórica dos campos e conceitos científicos mais relevantes para este estudo, passaremos à descrição da metodologia usada. Lembramos que constituiu nosso propósito analisar a imagem que os estudantes do ensino superior têm sobre a ciência, e assumimos que o modelo de análise foi construído com base na analogia das vogais proposta no artigo de Burns et al. (2003) "Science communication: a contemporary definition". Esta definição integra os seguintes fenómenos de reação à comunicação da atividade científica:

- notoriedade [awareness], que definimos como o grau de reconhecimento ou familiaridade que os públicos têm com novos aspetos da ciência;

- $\quad$ prazer [enjoyment] ou outras respostas afetivas, que identificamos como a reação de apreciar a ciência como entretenimento ou arte;

- interesse [interest], que explicamos como envolvimento voluntário com a ciência e a respetiva comunicação;

- opiniões [opinions], que identificamos com a formação, reformulação ou confirmação de atitudes relacionadas com a ciência;

- e compreensão [understanding] da ciência, que relacionamos com o entendimento dos seus conteúdos, processos e fatores sociais. 
Pretendemos, pois, verificar a presença/ausência destes efeitos de imagem nas perceções que os estudantes do ensino superior têm sobre a ciência. E com base nos estudos de Comunicação Estratégica e nos estudos de imagem, consideramos pertinente perceber que tipo de perceção(ões) existem sobre a ciência, a investigação científica e sobre os cientistas. Para o efeito, este estudo partiu da seguinte questão: que perceção têm os estudantes do ensino superior sobre a ciência? Já as questões secundárias para esta investigação foram enunciadas da seguinte forma:

QS1. Como podem os investigadores influenciar positivamente a imagem projetada da ciência?

QS2. Como podem as organizações científicas influenciar estrategicamente a imagem percebida da ciência junto dos estudantes?

QS3. Como pode o conhecimento da comunicação estratégica ajudar ao cumprimento do papel da comunicação da ciência?

Para obter algumas respostas iniciais (que poderiam ser úteis à realização de uma estudo mais alargado), conduzimos um estudo-piloto numa Instituição de Ensino Superior portuguesa, a Universidade do Minho. Esta investigação incluiu a aplicação de um inquérito online a alunos dos três ciclos de estudos na Universidade do Minho, tentando conhecer a sua perceção sobre a ciência e avaliar a evolução dessa representação ao longo dos três graus de ensino.

Os dados recolhidos contemplam as respostas obtidas no período entre 21 e 23 de outubro de 2015 , no total de 200 respostas validadas.

Modelo de análise

Tabela 1: Modelo de análise

\begin{tabular}{|l|l|l|}
\hline Fenómeno & Definição & Questão \\
\hline $\begin{array}{l}\text { Awareness } \\
\text { (Notoriedade) }\end{array}$ & $\begin{array}{l}\text { Reconhecimento } \\
\text { familiaridade com a } \\
\text { ciência }\end{array}$ & $\begin{array}{l}\text { - Quais das seguintes afirmações definem o termo } \\
\text { - Que imagem tens dos cientistas? }\end{array}$ \\
\hline $\begin{array}{l}\text { Enjoyment } \\
\text { (gozo/prazer) }\end{array}$ & $\begin{array}{l}\text { Respostas afetivas } \\
\text { apreciar a ciência como } \\
\text { entretenimento ou arte }\end{array}$ & $\begin{array}{l}\text { - Desenvolves trabalho científico fora do contexto das } \\
\text { - A ciência poderia ser a tua profissão de futuro? }\end{array}$ \\
\hline $\begin{array}{l}\text { Interest } \\
\text { (interesse) }\end{array}$ & $\begin{array}{l}\text { Envolvimento voluntário } \\
\text { com a ciência e/ou a sua } \\
\text { divulgação }\end{array}$ & $\begin{array}{l}\text { - Em que circunstâncias contactas com a ciência? } \\
\text { realiza na Universidade do Minho? }\end{array}$ \\
\hline
\end{tabular}




\begin{tabular}{|l|l|l|}
\hline $\begin{array}{l}\text { Opinions } \\
\text { (opiniões) }\end{array}$ & $\begin{array}{l}\text { Formação, reformulação } \\
\text { ou confirmação das } \\
\text { atitudes face à ciência }\end{array}$ & - Que opinião tens sobre a ciência? \\
\hline & $\begin{array}{l}\text { Perceber o conteúdo, } \\
\text { processos e fatores } \\
\text { sociais que interferem } \\
\text { com a ciência }\end{array}$ & - Escreve o nome de um cientista mundial que conheças \\
\hline
\end{tabular}

Ferramenta de análise

Como instrumento de recolha de dados para esta investigação, optámos pelo inquérito por questionário já que nos permitiu a recolha de informação sobre um grande número de sujeitos e a comparação entre as respostas obtidas. Aliás, Quivy e Campenhoudt (1992) apontam como um dos objetivos deste método, o conhecimento aprofundado de uma população - possível pela representatividade da amostra.

No caso específico do presente estudo, o questionário foi respondido diretamente pelos 200 alunos, em total confidencialidade, já que não tivemos acesso a informação sobre quem respondeu. Foi aplicado através de uma plataforma online, sendo distribuído através da divulgação de um link para o e-mail institucional dos alunos da Universidade do Minho. Considera-se a amostra representativa probabilística, já que não foram selecionados cursos específicos para responder e foram chamados a responder ao inquérito todos os alunos da Universidade do Minho.

O questionário, construído para este efeito, apresentou 14 perguntas, divididas em duas partes diferentes: (1) na primeira parte pretendeu-se traçar o perfil do estudante, com recurso às variáveis sexo; idade; curso e grau de ensino; (2) na segunda parte, com as restantes 10 questões, aferirem-se as diferentes impressões dos alunos sobre a Ciência, os cientistas e a carreira científica (as variáveis e a respetiva correspondência com a analogia das vogais está descrita na tabela acima).

No total das 14 perguntas, quatro eram de resposta aberta e 10 eram de resposta fechada. De entre estas 10 questões, uma foi dicotómica, duas foram de escolha múltipla (com possibilidade de seleção da opção 'não sei'); e as restantes sete questões foram de resposta múltipla, já que permitiram escolher mais do que uma opção de resposta.

\section{Resultados}

\section{Caracterização da amostra recolhida}

Entre os 200 respondentes deste questionário, 139 eram do sexo feminino (69,5\%) e 61 do sexo masculino (30,5\%). Relativamente à variável "idade", a distribuição por classes etárias está na tabela seguinte. Notese uma forte incidência do setor etário entre os 21 e os 29 anos, inclusive a média de idades dos respondentes foi de 24 anos, a moda é 21 e a mediana é de 22. 
Tabela 2: Idade

\begin{tabular}{|l|l|l|}
\hline Classe etária & Frequência & \% \\
\hline$[17-20]$ & 55 & $27,5 \%$ \\
\hline$[21-29]$ & 123 & $61,5 \%$ \\
\hline$[30-39]$ & 15 & $7,5 \%$ \\
\hline$[40-49]$ & 5 & $2,5 \%$ \\
\hline$[50-+]$ & 2 & $1 \%$ \\
\hline
\end{tabular}

Quanto à variável "curso" que os alunos respondentes estavam a frequentar, encontrámos 73 cursos diferentes representados na amostra, de várias áreas científicas, entre os 3 graus de ensino (Licenciatura, Mestrado e Doutoramento). A distribuição dos mesmos está na tabela abaixo, sendo importante ainda referir que os cursos com maior representatividade nas respostas foram: Ciências da Comunicação com 18 alunos, seguido da Medicina e da Psicologia, com 17 alunos cada.

Tabela 3: Curso

\begin{tabular}{|c|c|c|c|}
\hline Curso & Frequência & Curso & Frequência \\
\hline Administração pública & 2 & $\begin{array}{l}\text { Engenharia Eletrónica Industrial } \\
\text { e Computadores }\end{array}$ & 2 \\
\hline Biofísica e Bionanossistemas & 1 & Engenharia Industrial & 4 \\
\hline Bioinformática & 1 & Engenharia Informática & 6 \\
\hline Biologia Aplicada & 4 & Engenharia Mecânica & 3 \\
\hline $\begin{array}{l}\text { Biologia Molecular, Biotecnologia e } \\
\text { Bioempreendedorismo em plantas }\end{array}$ & 1 & Estatística & 1 \\
\hline Bioquímica & 5 & Estatística Aplicada & 1 \\
\hline Bioquímica Aplicada & 1 & Estudos Culturais & 3 \\
\hline Biotecnologia & 1 & Estudos da Criança & 4 \\
\hline Ciência Engenharia Polímeros & 1 & Estudos de Comunicação & 3 \\
\hline Ciência Política & 1 & Estudos de Gestão & 1 \\
\hline Ciências & 1 & Finanças & 1 \\
\hline Ciências da Comunicação & 18 & Genética Molecular & 9 \\
\hline Ciências da Educação & 2 & Gestão & 4 \\
\hline Ciências da Saúde & 1 & Gestão de Recursos Humanos & 4 \\
\hline Ciências do Ambiente & 1 & Gestão de Unidades de Saúde & 1 \\
\hline Comunicação, Arte e Cultura & 1 & História & 2 \\
\hline Contabilidade & 3 & Informática & 1 \\
\hline
\end{tabular}




\begin{tabular}{|c|c|c|c|}
\hline Design de Produto & 1 & $\begin{array}{l}\text { Intervenção Psicossocial com } \\
\text { Crianças, Jovens e Famílias }\end{array}$ & 1 \\
\hline Design e Marketing & 1 & Línguas Aplicadas & 1 \\
\hline Direito & 2 & Línguas e Literaturas Europeias & 2 \\
\hline Direito Tributário e Fiscal & 1 & Marketing & 3 \\
\hline Ecologia & 1 & Marketing e Estratégia & 3 \\
\hline Economia & 2 & Marketing PL & 1 \\
\hline Economia Industrial & 1 & Matemática e Computação & 2 \\
\hline $\begin{array}{l}\text { Economia Monetária, Bancária e } \\
\text { Financeira }\end{array}$ & 1 & Mediação Cultural e Literária & 1 \\
\hline $\begin{array}{l}\text { Educação - Formação, Trabalho e } \\
\text { Recursos Humanos }\end{array}$ & 1 & Medicina & 17 \\
\hline $\begin{array}{l}\text { Educação de Adultos e Intervenção } \\
\text { Comunitária }\end{array}$ & 1 & Micro e Nanotecnologias & 1 \\
\hline Electrónica Industrial & 1 & MOVRG & 1 \\
\hline Enfermagem & 6 & Negócios Internacionais & 1 \\
\hline Engenharia Biológica & 2 & Optometria e Ciências da Visão & 2 \\
\hline Engenharia Biomédica & 7 & Psicologia & 17 \\
\hline Engenharia Civil & 4 & Química & 1 \\
\hline Engenharia de Materiais & 1 & Química Medicinal & 1 \\
\hline Engenharia de Polímeros & 2 & Relações Internacionais & 1 \\
\hline $\begin{array}{l}\text { Engenharia e Gestão de Sistemas de } \\
\text { Informação }\end{array}$ & 3 & Sociologia & 4 \\
\hline Engenharia e Gestão Industrial & 4 & $\begin{array}{l}\text { Técnicas de Caracterização e } \\
\text { Análise Química }\end{array}$ & 2 \\
\hline Engenharia Eletrónica e Computadores & 1 & & \\
\hline
\end{tabular}

Quanto à variável "grau de escolaridade" de entre os 200 respondentes, 55 frequentavam a Licenciatura $(27,5 \%), 111$ o Mestrado/Mestrado Integrado (55,5\%) e 34 o Doutoramento (17\%)

As perceções sobre a ciência

Sobre a primeira questão - quais das seguintes afirmações definem o termo 'ciência'? - a resposta permitia a escolha de mais do que uma opção, pelo que os valores apresentados a seguir não são exclusivos e referem-se sempre à quantidade, percentagem ou proporção de alunos que selecionou a opção referida. 
Tabela 4: Quais as afirmações que definem o termo 'ciência'?

\begin{tabular}{|c|c|c|}
\hline Afirmação & Frequência & $\%$ \\
\hline A ciência é conhecimento & 179 & $89,5 \%$ \\
\hline A ciência resulta do trabalho desenvolvido nas universidades & 79 & $39,5 \%$ \\
\hline A ciência resulta do trabalho desenvolvido nos centros de investigação & 97 & $48,5 \%$ \\
\hline A ciência é um trabalho levado a cabo pelos professores universitários & 47 & $23,5 \%$ \\
\hline A ciência é um trabalho levado a cabo pelos investigadores & 90 & $45 \%$ \\
\hline A ciência pode ser desenvolvida em museus & 73 & $36,5 \%$ \\
\hline A ciência pode ser desenvolvida em hospitais & 95 & $47,5 \%$ \\
\hline A ciência estuda o mundo natural & 108 & $54 \%$ \\
\hline A ciência estuda o comportamento humano & 97 & $48,5 \%$ \\
\hline Outra. Qual? & 14 & $7 \%$ \\
\hline
\end{tabular}

Da análise do quadro, nota-se uma predominância inequívoca da visão da ciência como conhecimento, com quase $90 \%$ dos alunos a assinalarem esta resposta. Cerca de metade dos alunos consideraram que a ciência é desenvolvida nos centros de investigação (embora com um valor inferior ao esperado), pelos investigadores, e estuda o mundo natural e o comportamento humano. Uma percentagem um pouco menor de alunos considerou que a ciência é realizada nas universidades (a expectativa aqui era de um valor maior do que os 39,5\% obtidos) e em museus. Claramente abaixo da expectativa de resposta, ficou a opção de que a ciência é realizada por professores universitários, com pouco menos de $1 / 4$ dos alunos respondentes a considerarem este formato de produção do conhecimento, o que demonstra que os alunos julgam haver uma separação clara entre a atividade de docência e a ciência.

Esta questão tinha ainda um espaço para que os alunos pudessem escrever a sua opinião sobre como definem a ciência. Foram estas as respostas obtidas:

- Todas

- A ciência é o estudo de todos os seres vivos em geral

- $\quad$ p processo de produzir e reconstruir conhecimento

- A ciência estuda o comportamento humano, a maneira mais correta de interpretar o que nos rodeia

- É evolução

- A ciência procura explicações

- $\quad$ a ciência pode ser desenvolvida em vários contextos desde que respeite os princípios dos trabalhos científicos 
- A ciência estuda tudo, literalmente

- Pode resultar do trabalho e da experiência de muita gente

- A ciência pode ser desenvolvida em qualquer instituição e por qualquer pessoa, desde que transmita um aumento do conhecimento da sociedade

- A ciência é a edificação dos avanços no conhecimento da humanidade sobre o universo e si mesma, construído tijolo a tijolo sobre os ombros de mentes brilhantes

- A ciência é observação

- A ciência é o resultado da procura de respostas aos fenómenos naturais e sociais

- A ciência resulta do trabalho desenvolvido em empresas

Sobre a segunda questão - em que circunstâncias contactas com a ciência? -, lembramos novamente que dada a possibilidade aos alunos de escolherem mais do que uma opção, os valores apresentados a seguir não são exclusivos e referem-se sempre à quantidade, percentagem ou proporção de alunos que selecionou a opção referida.

Tabela 5: Em que circunstâncias contactas com a ciência?

\begin{tabular}{|l|l|l|}
\hline Afirmação & Frequência & $\%$ \\
\hline Nas aulas & 162 & $81 \%$ \\
\hline $\begin{array}{l}\text { Em palestras, seminários, colóquios, conferências ou } \\
\text { exposições }\end{array}$ & 154 & $77 \%$ \\
\hline Nos centros de investigação & 126 & $63 \%$ \\
\hline Nas bibliotecas (das universidades ou públicas) & 121 & $60,5 \%$ \\
\hline Em museus & 93 & $46,5 \%$ \\
\hline Em revistas e outras publicações científicas & 152 & $76 \%$ \\
\hline No cinema, literatura ou artes & 99 & $49,5 \%$ \\
\hline Nos jornais, televisão e rádio & 121 & $60,5 \%$ \\
\hline Em sites e redes sociais & 121 & $60,5 \%$ \\
\hline Na família & 46 & $23 \%$ \\
\hline Outra. Qual? & 6 & $3 \%$ \\
\hline
\end{tabular}

Com as respostas a esta questão, levanta-se o primeiro paradoxo desta investigação. Na resposta anterior, nem $25 \%$ dos alunos consideraram que a ciência seja resultado do trabalho desenvolvido pelos professores universitários, mas aqui já $81 \%$ consideraram que contactam com a ciência nas aulas (que lhes são 
ministradas pelos mesmos professores universitários). Ainda assim, os maiores índices de resposta aos momentos de contacto com a ciência, além da opção das aulas, concentrou-se nos eventos e nas publicações científicas, com cerca de $3 / 4$ dos alunos a escolherem estas possibilidades. Já não tão óbvio para estes alunos, é que o contacto com a ciência seja feito através dos centros de investigação (pode falar-se noutro paradoxo desta investigação, já que na maioria dos casos, são os próprios centros a fazer a divulgação da atividade científica, embora aqui possamos sempre apontar algum desconhecimento por parte dos alunos da existência dos centros de investigação dentro das universidades), das bibliotecas, dos jornais, televisão e rádio, dos sites e redes sociais, com um pouco mais de metade dos alunos a selecionarem estas opções. Abaixo dos $50 \%$ de respostas encontramos os museus (novamente abaixo da expectativa de resposta), o cinema, a literatura ou as artes, e mais abaixo ainda, o contacto através das famílias.

Tal como na questão anterior, foi dada a possibilidade dos alunos escreverem a própria opinião, onde encontramos outras ideias e algum humor. Eis as respostas:

- Em todo o lado

- No secundário, hospitais, telejornal

- No trabalho

- Tudo o que faço envolve ciência

- Estádio do Dragão

- Amigos

Sobre a terceira questão - que opinião tens sobre a ciência? - uma vez mais sublinhamos que foi dada a possibilidade aos alunos de escolherem mais do que uma opção, pelo que os valores apresentados a seguir não são exclusivos e referem-se sempre à quantidade, percentagem ou proporção de alunos que selecionou a opção referida.

Tabela 6: Que opinião tens sobre a ciência?

\begin{tabular}{|l|l|l|}
\hline Afirmação & Frequência & $\%$ \\
\hline A ciência é importante para todos os cidadãos & 180 & $90 \%$ \\
\hline A ciência cria problemas para a humanidade & 19 & $9,5 \%$ \\
\hline $\begin{array}{l}\text { A ciência é um trabalho mais adequado para homens do que para } \\
\text { mulheres }\end{array}$ & 1 & $0,5 \%$ \\
\hline As ciências 'puras' são mais rigorosas do que as ciências humanas e sociais & 37 & $18,5 \%$ \\
\hline A ciência é influenciada pela cultura e pela sociedade & 110 & $55 \%$ \\
\hline A pesquisa científica deve ser financiada pelos estados & 136 & $68 \%$ \\
\hline A informação científica tem impacto positivo na vida das populações & 132 & $66 \%$ \\
\hline
\end{tabular}




\begin{tabular}{|l|l|l|}
\hline O trabalho científico é fiável & 78 & $39 \%$ \\
\hline O investimento na ciência em Portugal é suficiente & 3 & $1,5 \%$ \\
\hline Os resultados da investigação científica deveriam ser partilhados & 135 & $67,5 \%$ \\
\hline Não tenho opinião & 0 & $0 \%$ \\
\hline Outra. Qual? & 4 & $2 \%$ \\
\hline
\end{tabular}

Nesta questão foram colocadas opções de resposta com impressões "positivas", "negativas" (para cobrir a possibilidade de resposta a afirmações discriminatórias) e "neutras" sobre a ciência. E aqui cumpre salientar o número significativo de respostas na opção "a ciência é importante para todos os cidadãos", uma das afirmações de impressão positiva, com a anuência de $90 \%$ dos alunos. Podemos, assim, afirmar que a ciência é reconhecida por estes alunos como muito relevante, que assumiram que todos os cidadãos podem beneficiar da mesma. Quanto às restantes impressões "positivas", um pouco aquém das expectativas ficou a resposta "a informação científica tem impacto positivo na vida das populações", com pouco mais de metade dos alunos, e mais abaixo ainda ficou a resposta "o trabalho científico é fiável" (muito abaixo dos pressuposto de pesquisa iniciais).

Quanto às impressões "negativas", consideramos que a expectativa de resposta e o índice obtido são bastante positivos (não se trata de nenhum paradoxo, já que sendo estas impressões negativas esperavamse à partida baixos índices de concordância, o que se verificou): menos de $10 \%$ dos alunos concordaram que "a ciência cria problemas para a humanidade" e nem $1 \%$ considerou que a Ciência é mais adequada para os homens do que para as mulheres.

As impressões "neutras" têm diferentes índices de resposta: na opção "as ciências 'puras' são mais rigorosas do que as ciências humanas e sociais", era expectável um valor abaixo do obtido que, ainda assim, não chegou a $1 / 5$ das respostas; as opções "a ciência é influenciada pela cultura e pela sociedade" e "a pesquisa científica deve ser financiada pelos estados" apresentaram valores consideráveis, com mais de metade dos alunos a considera-las como resposta possível; já a opção "o investimento na ciência em Portugal é suficiente" apresentou um valor bastante positivo, uma vez que apenas três alunos consideram que efetivamente o investimento feito na ciência é suficiente. Quanto à opção "os resultados da investigação científica deveriam ser partilhados" apresentou um valor aquém do que se esperava.

À semelhança das questões anteriores, também esta dava a possibilidade de os alunos manifestarem a sua opinião abertamente. Destacamos algumas das respostas bastantes positivas obtidas:

\section{- A ciência é o maior tesouro da humanidade}

- Nem todas as evidências são verdade, desde falsos positivos a manipulações propositadas de dados. "A estatística diz aquilo que se quer"

- A ciência não é valorizada como deveria

- O conhecimento científico faz evoluir a humanidade 
Sobre a quarta questão - em que consiste o trabalho da ciência? - manteve-se o cenário e demos a possibilidade aos alunos de escolherem mais do que uma opção, pelo que os valores apresentados a seguir não são exclusivos e referem-se sempre à quantidade, percentagem ou proporção de alunos que selecionou a opção referida.

Tabela 7: Em que consiste o trabalho da Ciência?

\begin{tabular}{|l|l|l|}
\hline Afirmação & Frequência & $\%$ \\
\hline $\begin{array}{l}\text { A ciência é uma extensão do conhecimento sobre uma determinada } \\
\text { matéria }\end{array}$ & 118 & $59 \%$ \\
\hline $\begin{array}{l}\text { A ciência envolve conhecimento exato, racional e verificável que se } \\
\text { expressa por leis }\end{array}$ & 79 & $69 \%$ \\
\hline A ciência é saber e erudição & 57 & $63 \%$ \\
\hline A ciência envolve criatividade & 101 & $50,5 \%$ \\
\hline A ciência prova ideias dos investigadores & 64 & $32 \%$ \\
\hline O conhecimento científico é imutável & 5 & $2,5 \%$ \\
\hline A ciência envolve observação e experimentação & 170 & $85 \%$ \\
\hline A ciência implica a análise crítica dos fenómenos & 152 & $76 \%$ \\
\hline O trabalho da ciência pode ser comercializado & 70 & $35 \%$ \\
\hline Outra. Qual? & 0 & $0 \%$ \\
\hline
\end{tabular}

Nesta questão, os maiores índices de resposta centram-se nas opções "a ciência envolve observação e experimentação" e "a ciência implica a análise crítica dos fenómenos", com mais de 3/4 dos alunos a assinalarem estas afirmações.

Um pouco abaixo deste valor, mas ainda assim acima dos $50 \%$ de resposta ficaram as opções "a ciência é uma extensão do conhecimento sobre uma determinada matéria"; "a ciência envolve conhecimento exato, racional e verificável que se expressa por leis"; "a ciência é saber e erudição"; "a ciência envolve criatividade". Abaixo de metade das respostas ficaram as opções "a ciência prova ideias dos investigadores"; "O trabalho da ciência pode ser comercializado". A opção " o conhecimento científico é imutável" deixou antever uma visão bastante positiva sobre a ciência, já que apenas 2,5\% destes 200 alunos considerou este opção como resposta acertada.

Pela profusão dos valores obtidos podemos afirmar que há já uma maior abertura para integrar na imagem pública da ciência as várias áreas científicas, para além do âmbito clássico das ciências 'puras'. Pode, portanto, falar-se de uma maior consciência social sobre a Ciência e sobre a atividade científica. 
Quanto à questão "desenvolves trabalho científico fora do contexto de aulas?", 53 alunos (26,5\%) afirmaram fazê-lo, contra 131 (65,5\%) que disse não o fazer. Já 16 alunos (8\%) declararam não saber se desenvolvem trabalho científico fora da sala de aula. Este é um indicador importante, pois demonstra que há ainda quem não saiba distinguir o trabalho científico do não-científico.

Foi ainda dada a opção dos alunos indicarem que atividade desenvolvem. Devido à disparidade de respostas, agregamos algumas por categoria e fizemos acertos na linguagem usada para criar maior coerência neste relatório:

- Teses de Doutoramento (5x)

- Teses de Mestrado (3x)

- Investigação e análise social que resulta em publicações

- Investigação na área dos Estudos de Rádio

- Investigação científica e participação em Projetos - inclusive bolsa de investigação (10x)

- Artigos em publicações científicas (3X)

- Aulas e investigação científica

- Sendo ciência para mim a troca de conhecimento, existe ciência em quase todas as interações com outros sujeitos

- Análise de fauna e flora para controlo de áreas maioritariamente florestais

- Pesquisas em grupos europeus de investigadores

- Leitura crítica de artigos científicos de forma a aumentar o conhecimento e gerar inspiração para o trabalho

- Experiências em laboratório

- Engenharia de software

- Canal educativo [Youtube]

- Monografias

- O trabalho científico vai muito além das aulas, e sendo uma aluna de doutoramento, as aulas não são onde se realiza o trabalho científico. Este é sempre realizado, por iniciativa minha, no âmbito do tema no qual me quero doutorar, ou noutros relacionados, que me tragam conhecimento.

- Estudos em contexto natural

Relativamente à questão "a ciência pode ser a tua profissão de futuro?", 111 alunos $(55,5 \%)$ responderam que sim; 32 (16\%) responderam que não e $57(28,5 \%)$ que não sabiam. A orientação das respostas é, pois, positiva, embora se deva ressalvar aqui que nenhum destes valores é vinculativo, já que alguns alunos podem ainda nem ter pensado no que fazer depois do término do curso.

Na sétima questão - que imagem tens dos cientistas? - repetimos o procedimento de permitir aos alunos escolherem mais do que uma opção. Assim, e uma vez mais, os valores apresentados a seguir não são exclusivos e referem-se sempre à quantidade, percentagem ou proporção de alunos que selecionou a opção referida. 
Tabela 8: Que imagem tens dos cientistas?

\begin{tabular}{|l|l|l|}
\hline Afirmação & Frequência & $\%$ \\
\hline $\begin{array}{l}\text { Os cientistas são bem recompensados financeiramente pelo seu } \\
\text { trabalho }\end{array}$ & 19 & $9,5 \%$ \\
\hline Os cientistas são professores universitários & 41 & $20,5 \%$ \\
\hline Os cientistas são especialistas contratados para a investigação & 99 & $49,5 \%$ \\
\hline Os cientistas são inventores & 76 & $38 \%$ \\
\hline Os cientistas são artistas & 60 & $30 \%$ \\
\hline Os cientistas têm uma carreira profissional & 101 & $50,5 \%$ \\
\hline Os cientistas trabalham em laboratórios especializados & 104 & $52 \%$ \\
\hline Os cientistas têm personalidades pouco emocionais & 12 & $6 \%$ \\
\hline Outra. Qual? & 24 & $12 \%$ \\
\hline
\end{tabular}

Nesta questão, apenas duas opções ficaram acima dos 50\% de resposta: "os cientistas trabalham em laboratórios especializados" e "os cientistas têm uma carreira profissional". Podemos apontar aqui algum desconhecimento, e até algumas ideias estereotipadas sobre o que é um cientista, qual o trabalho dos cientistas e sobre a carreira profissional dos mesmos (refiram-se aqui as respostas obtidas na questão anterior, em que, recorde-se, mais de $1 / 4$ dos alunos respondentes não sabe se quer seguir carreira na ciência e $16 \%$ afirmam não querer seguir esta carreira). As respostas obtidas nas opções seguintes demonstraram isso mesmo: "os cientistas são especialistas contratados para a investigação"; "os cientistas são inventores"; "os cientistas são artistas", "os cientistas têm personalidades pouco emocionais" e ainda "os cientistas são professores universitários" (novamente aparece o primeiro paradoxo apontado nesta investigação na questão sobre a definição do termo 'ciência'). No caso desta última opção, claramente estes mais de 41 alunos foram poucos a reconhecer os docentes universitários como cientistas (face ao que era esperado, claro). Num sentido mais positivo, nem $10 \%$ consideraram que os cientistas são bem recompensados pelo seu trabalho.

Nesta questão era ainda possível os alunos manifestarem a sua opinião sobre a imagem que tinham dos cientistas (novamente agregamos algumas respostas similares):

- Não são reconhecidos pelo seu trabalho. E não existe, em Portugal, uma carreira científica bem remunerada e que esteja sujeita a progressão

- Os cientistas são investigadores com um enorme conhecimento

- Não tenho $(2 x)$

- Mal remunerados (3x)

- Nenhuma destas é aplicável, para ser honesto 
- Os cientistas procuram conhecimento

- Os cientistas contribuem para a compreensão do mundo que nos rodeia em todas as suas vertentes

- Os cientistas são muito importantes no desenvolvimento de uma nação

- Os cientistas são pessoas emocionalmente e socialmente equilibradas e embora mal remunerados na maioria dos casos fazem o melhor para o conhecimento da realidade que nos rodeia e para 0 bem da humanidade

- Os cientistas vão para o desemprego

- Os cientistas são pouco reconhecidos e mal remunerados

- Os cientistas não têm o seu valor devidamente reconhecido

- Pouco valorizados pela sociedade na sua generalidade

- Os cientistas são investigadores. São pessoas que revelam ciência

- Muitos investigadores empregam-se como professores universitários quando na verdade apenas querem fazer investigação, mas vêem-se obrigados a dar aulas para obterem "financiamento"..

- Os cientistas são maltratados pela sociedade

- São meio malucos :)

- Os cientistas dedicam-se de corpo e alma à investigação e o seu trabalho é pouco valorizado e reconhecido na sociedade. São poucos os que conseguem atingir esse patamar de notoriedade!

- Os cientistas são pessoas ditas "normais" que desenvolvem a sua profissão num âmbito específico

- Os cientistas são mal pagos, e fazem ciência pela ambição do conhecimento

- Os cientistas são todos aqueles que investigam a natureza

- São pessoas que se envolvem na busca de conhecimento

A oitava questão era na verdade um pedido - escreve o nome de um cientista mundial que conheças - e eis os resultados:

Tabela 9: Escreve o nome de um cientista mundial que conheças

\begin{tabular}{|l|l|l|l|}
\hline Nome do cientista & Frequência & Nome do cientista & Frequência \\
\hline $\begin{array}{l}\text { Não sabe/não responde/ não } \\
\text { conhece }\end{array}$ & 5 & Louis Pasteur & 2 \\
\hline Albert Bandura & 1 & Luc Ferry & 1 \\
\hline Albert Einstein & 53 & Marie Curie & 15 \\
\hline Anthony Giddens & 1 & Martin Fowler & 1 \\
\hline António Damásio & 2 & Margaret Mead & 1 \\
\hline Aristóteles & 2 & Mary Herbert & 1 \\
\hline August Comt & 1 & Max Weber & 1 \\
\hline Bill Nye & 1 & Michael Mann & 1 \\
\hline Carl Sagan & 2 & Michael Otto & 1 \\
\hline Carl Woese & 1 & Michel Foucault & 1 \\
\hline Charles Darwin & 5 & Michio Kaku & 1 \\
\hline Christiaan Huygens & 1 & Miguel Nicolelis & 1 \\
\hline
\end{tabular}




\begin{tabular}{|c|c|c|c|}
\hline Craig Venter & 1 & Neil deGrass Tyson & 2 \\
\hline Daniel Kahenam & 1 & Nicolau Copérnico & 2 \\
\hline Denis McQuail & 1 & Nikola Tesla & 4 \\
\hline Émile Durkheim & 1 & Noam Chomsky & 1 \\
\hline Elizabeth Loftus & 1 & Norbert Elias & 1 \\
\hline Eric Betzig & 1 & Otto Hahn & 1 \\
\hline Eric Lander & 1 & Paul Krugman & 1 \\
\hline Faraday & 1 & Peter Atkins & 1 \\
\hline Fernando Gonzáles Rey & 1 & Peter Michael & 1 \\
\hline Fwa Tien Fang & 1 & Philip Kotler & 1 \\
\hline Galileu Galilei & 1 & Quintanilha & 1 \\
\hline Gary Kreps & 1 & Richard Dawkins & 1 \\
\hline Gauss & 1 & Richard Feynman & 1 \\
\hline Greenhaus & 1 & Stanley B. Prusiner & 1 \\
\hline Gregor Mendel & 1 & Stephen Hawking & 32 \\
\hline Isaac Newton & 19 & Steve Graham & 1 \\
\hline James Clerk Maxwell & 2 & Takaaki Kajita & 1 \\
\hline Jean Marie-Lehn & 1 & Thomas Edison & 2 \\
\hline Kimura & 1 & Thomas Herzog & 1 \\
\hline Lawrence Krauss & 1 & Tony Walter & 1 \\
\hline Loïc Wacquant & 1 & Willem Doise & 1 \\
\hline
\end{tabular}

Nota-se uma predominância, sem grande surpresa, de Albert Einstein (porventura quem melhor personifica os estereótipos ligados à profissão de cientista), a ser identificado por um pouco mais de $1 / 4$ dos alunos; Stephen Hawkin, identificado por $16 \%$ dos alunos e Isaac Newton por $10 \%$ dos alunos.

A nona questão renovava o pedido para Portugal: escreve o nome de um cientista nacional que conheças. 


\begin{tabular}{|c|c|c|c|}
\hline Nome & Frequência & Nome & Frequência \\
\hline Não sabe/não responde/ não conhece & 25 & João Ribeiro & 1 \\
\hline Aarão Ferreira Lacerda & 1 & Joana Gaspar & 1 \\
\hline Abel Salazar & 6 & Joaquim Barros & 1 \\
\hline Albertino Gonçalves & 1 & Jorge Vala & 2 \\
\hline Alexandre Quintanilha & 7 & José Covas & 1 \\
\hline Álvaro Macieira-Coelho & 2 & José Creissac Campos & 1 \\
\hline Ana Júlia Cavaleiro & 1 & José Nuno Oliveira & 1 \\
\hline Ana Paula Martins & 1 & José Xavier & 1 \\
\hline Ana Preto & 1 & Licínio Lima & 1 \\
\hline Anabela Carvalho & 1 & Lino Ferreira & 1 \\
\hline António Barreto & 1 & Luís Aguiar Conraria & 1 \\
\hline António Coutinho & 1 & Luís Archer & 1 \\
\hline António Damásio & 19 & Luis Moita & 1 \\
\hline António Egas Moniz & 11 & Luiz Saldanha & 1 \\
\hline António Gedeão & 1 & Luís Viseu Melo & 2 \\
\hline António Lobo Antunes & 2 & Manuela Gomes & 1 \\
\hline António Manuel Baptista & 1 & Maria Mota & 1 \\
\hline António Pinto-Duarte & 10 & Mariana Henriques & 1 \\
\hline Augusto Santos Silva & 1 & Mário Sousa & 1 \\
\hline Aurélio Quintanilha & 1 & Moisés Espírito Santo & 1 \\
\hline Bartolomeu de Gusmão & 1 & Moisés Martins & 2 \\
\hline Bento Caraças & 1 & Noel de Miranda & 2 \\
\hline Boaventura Sousa Santos & 4 & Nuno Crato & 1 \\
\hline Bruno Silva Santos & 1 & $\begin{array}{l}\text { O doutor que é irmão do Pinto } \\
\text { Da Costa }\end{array}$ & 1 \\
\hline Carlos Caldas & 2 & Patrícia Maciel & 1 \\
\hline Carlos Fiolhais & 7 & Pedro Álvares Cabral & 1 \\
\hline Carlos Silva & 1 & Pedro Andrade & 1 \\
\hline Carolina Natal & 1 & Pedro Mangueijo & 1 \\
\hline Cátia Silva & 1 & Pedro Morgado & 1 \\
\hline Chambell & 1 & Pedro Nunes & 12 \\
\hline Cidália Castro & 1 & Pedro Silva & 1 \\
\hline Cristina Ponte & 1 & Quintanilha & 1 \\
\hline Eduardo Marques & 1 & Renata Gomes & 1 \\
\hline Elvira Fortunato & 3 & Ricardo Jorge (INSA) & 1 \\
\hline Fernando Carvalho Rodrigues & 1 & Rita Guerreiro & 1 \\
\hline Graça Raposo & 1 & Ronaldo Sousa & 1 \\
\hline Hanna Damásio & 1 & Rosa Cabecinhas & 1 \\
\hline Helder Maiato & 1 & Rui L. Reis & 10 \\
\hline
\end{tabular}




\begin{tabular}{|l|l|l|l|l|}
\hline Henrique Veiga-Fernandes & 1 & Sedas Nunes & 1 \\
\hline Hermínio Martins & 1 & & Teresa Ruão & 2 \\
\hline João Amado & 1 & Tiago Rodrigues & 1 \\
\hline João de Espregueira Mendes & 1 & & Tony Collins & 1 \\
\hline João Guimarães & 1 & Vitorino Magalhães Godinho & 1 \\
\hline João Lupi & 1 & William Machado & 1 \\
\hline João Magueijo & 2 & Zita Martins & 1 \\
\hline João Mano & 2 & & & \\
\hline
\end{tabular}

Tabela 10: Escreve o nome de um cientista nacional que conheças

Não podemos deixar de fazer o seguinte apontamento nesta questão: o maior índice de resposta obtido surgiu na opção de 'não sabe/não responde/não conhece'. É, talvez, inquietante que $12,5 \%$ dos alunos não saibam identificar um cientista português. Os cientistas portugueses mais identificados pelos alunos foram António Damásio, Pedro Nunes, Rui L. Reis e António Pinto-Duarte.

A última questão foi enunciada da seguinte forma: "como tomas conhecimento do trabalho científico que se realiza na Universidade do Minho?". Aqui, novamente, foi permitida a escolha de mais do que uma opção.

Tabela 11: Como tomas conhecimento do trabalho científico que se realiza na Universidade do Minho?

\begin{tabular}{|l|l|l|}
\hline Afirmação & Frequência & $\%$ \\
\hline Através de familiares e amigos & 27 & $13,5 \%$ \\
\hline Através de notícias na televisão, jornais ou rádio & 117 & $58,5 \%$ \\
\hline $\begin{array}{l}\text { Através do website ou página de Facebook da UMinho (ou dos } \\
\text { seus cursos) }\end{array}$ & 135 & $67,5 \%$ \\
\hline Através das publicações científicas & 107 & $53,5 \%$ \\
\hline Através dos centros de investigação da UMinho & 101 & $50,5 \%$ \\
\hline $\begin{array}{l}\text { Em congressos, palestras, seminários e exposições realizados } \\
\text { na UMinho }\end{array}$ & 111 & $55,5 \%$ \\
\hline Nas aulas & 118 & $\mathbf{5} \%$ \\
\hline Em feiras de ensino superior & 6 & $3 \%$ \\
\hline Outra. Qual? & 2 & \\
\hline
\end{tabular}

Dada a possibilidade aos alunos de escolherem mais do que uma opção, os valores discutidos a seguir não são exclusivos e referem-se sempre à quantidade, percentagem ou proporção de alunos que selecionou a opção referida.

O website e a página do Facebook da Universidade do Minho são as formas mais populares de contacto com a ciência desenvolvida na instituição, logo seguidos (por ordem decrescente) das aulas, notícias na televisão, 
jornais ou rádio, eventos científicos, publicações científicas e dos centros de investigação (novamente um índice abaixo do esperado, podendo falar-se do desconhecimento por parte dos alunos da existência e do trabalho dos centros), embora todas estas formas de contacto com a Ciência estejam com mais de 50\% de respostas. Com índices bastante baixos (e mesmo aquém do que era esperado face a estudos anteriores), ficaram os familiares e amigos (em linha com o que já foi dito acima, quando o alunos indicaram de que forma contactavam com a Ciência também nessa questão, a opção dos familiares e amigos teve um índice de resposta baixo) e as feiras de ensino superior.

Os alunos escreveram as seguintes afirmações na resposta 'Outra. Qual?':

- $\quad$ Contacto com professores

- Nenhuma

\section{Síntese conclusiva}

Depois da exposição dos resultados obtidos com o inquérito por questionário, e relembrando que este era apenas um estudo-piloto, estamos agora em condições de afirmar o seguinte: estar informado sobre a ciência ou contactar diretamente com a sua atividade não gera, automaticamente, uma perceção positiva sobre a mesma. As fontes de informação e contacto são múltiplas, expondo os recetores a mensagens complexas e nem sempre coerentes. Tal aumenta a responsabilidade das instituições de produção científica na comunicação com a sociedade, mas torna o seu papel ainda mais difícil.

O ponto de partida desta investigação era perceber que imagem têm os estudantes do Ensino Superior da atividade científica. Vimos, na revisão teórica, que a imagem é um fenómeno muito complexo, enquanto conjunto de perceções (negativas/positivas) sobre um determinado assunto ou objeto. E foi esse entendimento que usámos para analisar o caso da imagem da Ciência em Portugal, em particular as impressões que reúnem os alunos da Universidade do Minho. E em resultado do estudo, podemos afirmar que, de uma forma global, esse conjunto de representações mentais dos jovens é: largamente positivo, embora algo distante da realidade que expõem e, com frequência, enviesado porque ainda atravessados por visões distorcidas da realidade (como no caso do não reconhecimento dos docentes universitários como cientistas).

Face a estes dados, reiteramos a nossa ideia inicial de que a imagem da ciência pode ser trabalhada com o auxílio dos conhecimentos já produzidos nos dois campos científicos: a Comunicação da Ciência e a Comunicação Estratégica. E eis algumas dimensões estratégicas de gestão da comunicação da ciência que identificamos, desde já:

1. profissionalizar o trabalho de comunicação da ciência (atribuindo a função a profissionais especializados em comunicação);

2. atuar sobre dimensões segmentadas da imagem da ciência, do cientista e da carreira científica;

3. auxiliar os investigadores/cientistas no processo de divulgação do seu trabalho;

4. promover eventos científicos abertos à sociedade;

5. investir na promoção do trabalho realizado nos centros de investigação;

6. promover um maior contacto com os públicos jovens através das plataformas online mais populares, como os websites e a páginas de Facebook; 
7. atrair mais jovens para a investigação científica (e para o ensino superior).

E para cumprir estes enunciados estratégicos, eis alguns eixos de comunicação a explorar:

Figura 1: Eixos de comunicação da Ciência

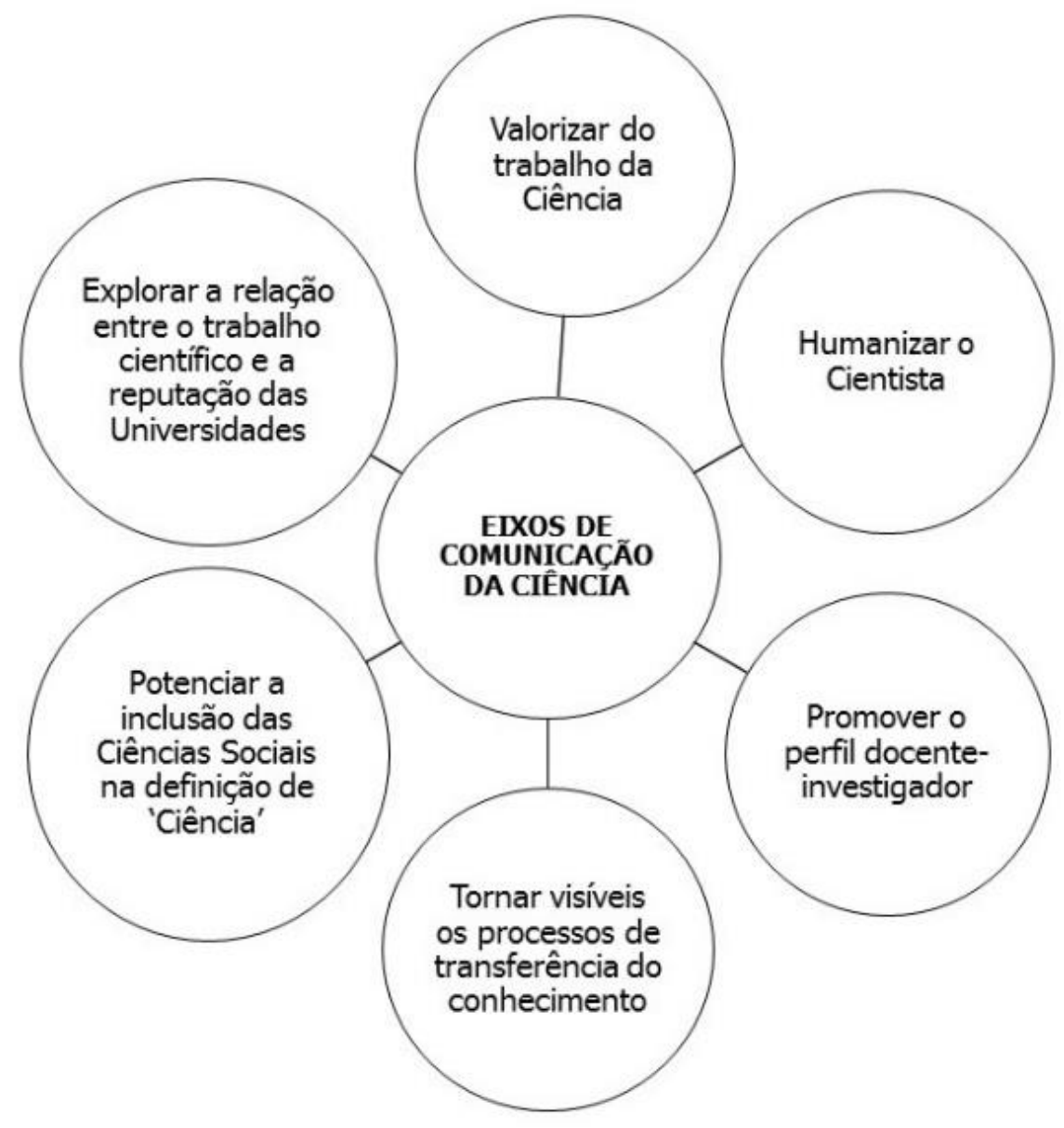

Estas vertentes podem e devem ser trabalhadas no contexto da comunicação estratégica da ciência, atividade que tem como objetivo - defendemos nós - obter melhores resultados (a) na divulgação, criação e gestão do valor simbólico da ciência, do cientista e da profissão; (b) na promoção de uma cultura científica - balizada pelos valores que regem a ciência e a investigação, como rigor, isenção, objetividade, clareza -; (c) na recriação da identidade da ciência, que corresponda aos desafios da sociedade atual; (d) na criação e manutenção de uma imagem/reputação positivas da ciência e dos cientistas; e (d) no auxílio à concretização da missão social da ciência que é a de ser uma atividade que propicia a evolução social, económica, política e cultural de uma qualquer comunidade.

Ainda assim, e porque este foi um estudo-piloto, consideramos pertinente aprofundar as questões, que nos orientaram até aqui, em estudos futuros e que são: como podem os investigadores influenciar positivamente a imagem projetada da ciência? Como podem as instituições influenciar estrategicamente a imagem percebida da ciência? E como a comunicação estratégica ajudar a missão da comunicação da ciência? 


\section{Referências bibliográficas}

Argenti, P. A., Howell, R. A. \& Beck, K. A. (2005). The strategic commnication imperative. MIT Sloan Mangement Review, 46(3), 83-89.

Bauer, M. W. (2008). Paradigm change for science communication: commercial science needs a critical public. In D. Cheng, M. Claessens, T. Gascoigne, J. Metcalfe, B. Schiele \& S. Shi (Eds.), Communicating science in social contexts. New models, new practices (pp. 7-26). Holanda: Springer.

Bryant, C. (2003). Does Australia need a more effective policy of science communication? International Journal for Parasitology, 33, 357-361.

Burns, T. W., O'Connor, D. J. \& Stocklmayer, S. M. (2003). Science communication: a contemporary definition. Public Understanding of Science, 12, 183-202. doi: 10.1177/09636625030122004

Carrillo, M. V. (2014). Comunicação Estratégica no ambiente comunicativo das organizações atuais. Comunicação e Sociedade, 26, 71-80. doi: 10.17231/comsoc.26(2014).2025

Csermely, P. (2003). Recruiting the younger generation to science. EMBO Reports, 4(9), 825-828. doi: $10.1038 /$ sj.embor.embor927

Davies, S. R. \& Horst, M. (2016). Science communication: culture identity and citizenship. Londres: Palgrave Macmillan. doi: 10.1057/978-1-137-50366-4

Dowling, G. (1986). Manging your corporate image. Industrial Marketing Management, 15(2), 109-115.

Epstein, I. (1998). Comunicação da ciência. São Paulo em Perspectiva, 12(4), 60-68.

Fernandes, J. L. (2011). Perspectivas sobre os discursos da divulgação da ciência. Exedra, [número especial Comunicação nas Organizações], 93-106. Retirado de http://www.exedrajournal.com/docs/sCO/05-93-106.pdf

Fischhoff, B. \& Scheufele, D. A. (2013). The science of science communication. PNAS - Proceedings of the National Academy of Sciences of the United States of America, 110(suppl. 3), 14031-14032). doi: 10.1073/pnas.1312080110

Granado, A. \& Malheiros, J. V. (2015). Cultura científica em Portugal: ferramentas para perceber o mundo e aprender a mudá-lo. Lisboa: Fundação Francisco Manuel dos Santos.

Gregory, J. \& Miller, S. (1998a). Science in public: communication, culture and credibility. Nova Iorque: Plenum Trade.

Gregory, J. \& Miller, S. (1998b). The public understanding of science. In A. Wilson (Ed.), The handbook of communication science (pp. 3-16). Bristol: Institute of Physics.

Hernando, M. C. (2006). Funciones de la divulgacion. Retirado de http://www.manuelcalvohernando.es/articulo.php?id $=67$

Horst, M., Davies, S. R. \& Irwin, A. (2017). Reframing science communication. In U. Felt, R. Fouché, C. A. Miller \& L. Smith-Doerr (Eds.), The handbook of science and technology studies (pp. 881-907). Cambridge: MIT Press.

Jenkins, E. W. (1994). Scientific literacy. In T. Husen \& T. N. Postlethwaite (Eds.), The International encyclopedia of education (vol.9 pp. 5345-5350). Oxford: Pergamon Press.

Kennedy, S. H. (1977). Nurturing corporate images: total communication or ego trip. European Journal of Marketing, 11(3), 119-164.

Kunsch, M. (1986). Planejamento de relações públicas na comunicação integrada. São Paulo: Summus. 
Magalhães, R. (2014). A Comunicação da Ciência e as estratégias online. O caso do Centro de Estudos de Comunicação e Sociedade. Dissertação de Mestrado em Ciências da Comunicação. Braga: Universidade do Minho. Retirado de http://hdl.handle.net/1822/33469

Magalhães, R. (2015). A comunicação estratégica aplicada à divulgação da ciência. O caso do Centro de Estudos de Comunicação e Sociedade. Observatorio (OBS*) Journal, 9(4), 51-84. doi: 10.15847/obsOBS942015850

Martins, I. P. (2015). Ciência, público e compreensão pública da ciência. Interacções, 39, 36-48. Retirado de http://revistas.rcaap.pt/interaccoes/article/view/8721

Quivy, R. \& Campenhoudt, L. V. (1992). Manual de investigação em Ciências Sociais. Lisboa: Gradiva.

Ruão, T. (2008). A Comunicação Organizacional e os fenómenos de identidade: a aventura comunicativa da formação da Universidade do Minho, 1974-2006. Tese de Doutoramento em Ciências da Comunicação, Universidade do Minho, Braga, Portugal. Retirado de http://hdl.handle.net/1822/8841

Ruão (2016). A organização comunicativa: teoria e prática em Comunicação Organizacional. Braga: CECS. Retirado de https://tinyurl.com/y8yrtbxn

Ruão, T., Neves, I. C., Botelho, G. \& Nogueira, P. (2012). Science image in Portugal: studying high school students. Observatório (OBS*) Journal, 6, 169-179. doi: 10.7458/obs642012628

Ruão, T., Neves, I. C. \& Magalhães, R. (2015). Science and strategic communication: how can universities attract high school students? In A. D. Melo, I. Sommerville \& G. Gonçalves (Eds.), Organisational and Strategic Communication research: European perspectives II (pp. 111-128). Braga: CECS. Retirado de http://www.lasics.uminho.pt/ojs/index.php/cecs ebooks/article/view/2082

Skinner, G. \& Shah, J. N. (2014). Understanding public attitudes to science. Significance,11, 3, 14-18. doi: 10.1111/j.1740-9713.2014.00748.x

Schultz, M., Hatch, M. J. \& Larsen, M, H. (2000). The expresive organization: linking identity, reputation and corporate branding. New York: Oxford University Press.

Tintori, A. (2017a). The most common stereotypes about science and scientists: what scholars know. In A. Tintori \& R. Palomba, Turn on the light on science: a research-based guide to break down popular stereotypes about science and scientists (pp. 1-18). Londres: Ubiquity Press. doi: 10.5334/bba.b

Tintori, A. (2017b). Can people really change their opinion about scientists? In A. Tintori \& R. Palomba, Turn on the light on science: a research-based guide to break down popular stereotypes about science and scientists (pp. 65-88). Londres: Ubiquity Press. doi: 10.5334/bba.e

Villafañe, J. (1996). Introducción a la teoria de la imagen. Madrid: Ediciones Pirámides.

Villafañe, J. (1998). Imagen positiva. Gestión estratégica de la imagen de las empresas. Madrid: Ediciones Pirámides. 